\title{
The effect of metformin on TSH levels in euthyroid and hypothyroid newly diagnosed diabetes mellitus type 2 patients
}

\author{
Dimic D, Velojic Golubovic M, Radenkovic S, Radojkovic D, Pesic M \\ Clinic of Endocrinology, Clinical Center Niš, Niš, Serbia. dimicdr@gmail.com
}

\begin{abstract}
INTRODUCTION: Metformin is the first-line oral hypoglycemic agent in the treatment of type 2 diabetes mellitus with a number of positive effects. The aim of the study was to determine the effect of metformin on TSH levels in euthyroid and hypothyroid newly diagnosed diabetes mellitus type 2 patients.

MATERIAL AND METHODS: The study included 255 newly diagnosed diabetes mellitus type 2 drug naive patients, 170 euthyroid patinets, group A, 85 hypothiroid patients, group B, and 80 euthyroid DM type 2 patients on metformin therapy for more than 5 years, group $\mathrm{C}$. Patients in groups $\mathrm{A}$ and $\mathrm{B}$ began metformin treatment with a dose of $2000 \mathrm{mg} /$ day. We assessed baseline TSH, FT3, FT4 levels and TPOab, in groups A, B and C, and 6 months after initiation of metformin therapy in groups $A$ and $B$.

RESULTS: There were no differences in FT3 and FT4 levels after 6 months of metformin treatment in all groups. TSH level in Group A showed some reduction after 6 months of metformin therapy, not statistically significant. The only statistically significant change in Group A is the change of TSH level after 6 months in TPOAb positive patients. There was statiscically significant decrease in TSH level after 6 months in group $\mathrm{B}$. There were no significant differences of basal TSH, FT3 and FT4 levels in groups A and B compared to group C.

CONCLUSION: The results show that metformin has TSH lowering effect in patients with type 2 DM and hypothyreoidism, but also in euthyroid TPOab positive, levothyroxine naive patients. We have shown that the TSH lowering effect of metformin is not dependent on long term metformin therapy (Tab. 2, Ref. 18). Text in PDF www.elis.sk. KEY WORDS: metformin, TSH, diabetes mellitus type 2.
\end{abstract}

\section{Introduction}

Diabetes and thyroid function disorders are the most common endocrine diseases. The existence of hypothyroidism in patients with diabetes is much more common than in people without diabetes and ranges from $10-30 \%(1,2)$. Connection between these two endocrinopathies is not entirely clear. Metformin is the first-line oral hypoglycemic agent in treatment of type 2 diabetes mellitus with a number of positive effects, with a good drug safety profile. Metformin reduces the hepatic and peripheral insulin resistance, decreases hepatic glucose production, increases muscle glucose uptake, leading to low apetite and body weight reduction (3). Besides these metabolic effects, metformin inducec modulation of AMPK activity inhibiting also the progression of different cancers, including thyroid cancer, and modulates iodine uptake through thyroidal sodium-iodide symporter (4). However, there are data on the effect of metformin on thyroid stimulating hormone (TSH) level with subsequent reduction below the reference values, but without clinical signs of hyperthyroidism and changes of FT4 and FT3. In patients with hypothyroidism on stable dose of 1-thyroxine therapy

Clinic of Endocrinology, Clinical Center Niš, Niš, Serbia

Address for correspondence: D. Dimic, Clinic of Endocrinology, Clinical Center Niš, bul.dr Zoran Djindjić 48, 18000 Niš, Serbia.

Phone: +381631094024, Fax: +381184533310 and in untreated subjects, as well as in patients with polycystic ovaries metformin reduces TSH level $(5,6)$, while data of the effect of metformin in euthyroid patients are contradictory, reporting both reduction and increase of TSH level (7). Some reports suggest that, to some extent, the metformin effect on TSH secretion could depend on the hormone circulating concentration (8). The mechanism of these changes is not clear. The aim of the study was to determine the effect of metformin on TSH levels in euthyroid and hypothyroid newly diagnosed diabetes mellitus type 2 patients.

\section{Material and methods}

The study included 255 newly diagnosed diabetes mellitus type 2 drug naive patients, as well as 80 euthyroid diabetes mellitus type 2 patients being on metformin therapy for more than 5 years, Group C. All patients were treated at the Clinic of Endocrinology, Clinical center Niš, in 2014 and 2015. Patients with newly detected diabetes were divided into two groups. Group A included 170 patients with normal thyroid function based on basal TSH, FT4 and FT3, and Group B included 85 patients with a previous diagnosis of primary hypothyroidism in stable 1 thyroxine therapy for more than 6 months. Group A is divided into two subgroups according to baseline TSH levels before therapy with metformin, with TSH levels lower than 2 and with TSH levels between 2-4.6 $\mathrm{mU} / \mathrm{l}$, and in two subgroups according to TPOab positivity. Pa- 
Tab. 1. TSH, fT4, fT3 and TPOab values in Group A, Group B and Group C before and after 6 months on metformin treatment.

\begin{tabular}{|c|c|c|c|c|c|c|}
\hline \multirow{2}{*}{ Group A } & \multicolumn{2}{|c|}{ TSH } & \multicolumn{2}{|c|}{ fT4 } & \multicolumn{2}{|c|}{ fT3 } \\
\hline & Baseline & After 6 months & Baseline & After 6 months & Baseline & After 6 months \\
\hline $\mathrm{TSH}<2$ & $1.23 \pm 0.56$ & $1.18 \pm 0.63$ & $11.51 \pm 2.32$ & $11.03 \pm 2.89$ & $2.18 \pm 0.57$ & $2.09 \pm 0.48$ \\
\hline TSH 2-4 & $2.97 \pm 0.89$ & $2.46 \pm 0.97$ & $10.56 \pm 2.69$ & $10.67 \pm 3.00$ & $2.01 \pm 0.62$ & $2.03 \pm 0.78$ \\
\hline TPOab + & $2.32 \pm 1.20$ & $1.65 \pm 1.76^{*}$ & $10.49 \pm 3.01$ & $10.57 \pm 3.11$ & $1.98 \pm 0.85$ & $2.02 \pm 0.66$ \\
\hline TPOab - & $2.11 \pm 1.31$ & $2.19 \pm 1.40$ & $11.74 \pm 2.33$ & $11.34 \pm 2.94$ & $2.19 \pm 0.51$ & $2.11 \pm 0.75$ \\
\hline
\end{tabular}

$* \mathrm{p}<0.001$ vs Group B baseline, $* * \mathrm{p}<0.05$ vs Group A after 6 months

Tab. 2. TSH, FT4 and FT3 values baseline and after 6 months on metformin treatment in group according to TSH basline levels and TPOab positivity.

\begin{tabular}{|c|c|c|c|c|c|c|}
\hline & \multicolumn{2}{|c|}{$\mathrm{TSH} \mathrm{mU} / 1$} & \multicolumn{2}{|c|}{$\mathrm{fT} 4 \mathrm{pmol} / 1$} & \multicolumn{2}{|c|}{$\mathrm{fT} 3 \mathrm{pmol} / \mathrm{l}$} \\
\hline & Baseline & After 6 months & Baseline & After 6 months & Baseline & After 6 months \\
\hline Group A & $2.17 \pm 1.13$ & $1.99 \pm 1.42$ & $11.36 \pm 2.58$ & $10.88 \pm 2.01$ & $2.13 \pm 0.62$ & $2.06 \pm 0.41$ \\
\hline Group B & $2.54 \pm 0.97$ & $1.29 \pm 0.74 * * *$ & $10.42 \pm 1.79$ & $10.99 \pm 2.45$ & $2.21 \pm 0.66$ & $2.24 \pm 0.59$ \\
\hline Group C & $1.98 \pm 1.24$ & & $9.95 \pm 2.47$ & & $2.27 \pm 0.72$ & \\
\hline
\end{tabular}

$* \mathrm{p}<0.05$ vs TPOab + baseline

tients in groups A and B began metformin treatment with a daily $2000 \mathrm{mg}$ dose. In all patients, the blood was sampled to TSH, FT3, FT4 levels and TPOab, at baseline before starting the treatment of group $\mathrm{A}$ and $\mathrm{B}$, and in group $\mathrm{C}$, and 6 months after initiation of metformin therapy in groups A and B. All hormones levels were assessed at the Institute of Biochemistry, Clinical Center Nis on Beckman UNICELL DXI 600 - chemiluminiscent method. The reference ranges are for TSH $0.40-4.60 \mathrm{mU} / 1$, for FT4 7-16 pmol / 1, for FT3 1.4-3.5 pmol / 1 and TPOAb $<14$. The results were expressed as mean \pm standard errors mean (S.E.M.). The significance of differences between the groups was determined by the Least Significant Difference (LSD) test. Statistically significant differences were assumed at $\mathrm{p}$ less or equal to 0.05 .

All subjects gave their informed consent to the study which was performed in accordance with good clinical practice and Declaration of Helsinki. Local ethical review committee was informed and there were no ethical concerns on the study.

\section{Results}

There were no differences in the FT3 and FT4 hormone levels after 6 months of metformin treatment compared to baseline values in all groups. The results are shown in Table 1. TSH level in Group A showed reduction after 6 months of metformin therapy, with $2.17 \pm 1.13$ to $1.99 \pm 1.42 \mathrm{~m} / \mathrm{l}$, which is not statistically significant. Somewhat greater decrease in TSH levels after 6 months of metformin therapy, from $2.97 \pm 0.89$ to $2: 46 \pm 0.97 \mathrm{~m} / 1$ was observed in patients with basal TSH values higher than $2 \mathrm{U} / 1$, but did not reach statistical significance. The only statistically significant change in Group A is the change of TSH level after 6 months of metformin therapy, from $2.32 \pm 1.65$ to $1.20 \pm 1.76 \mathrm{~m} / 1, \mathrm{p}<$ 0.05 in TPOAb positive patients of this group (Tab. 2). In group $\mathrm{B}$, there was statiscically significant decrease in TSH level after 6 months of metformin therapy, as compared to baseline value, by $2.54 \pm 0.97$ to $1.29 \pm 0.74 \mathrm{mU} / 1, \mathrm{p}<0.001$, and in relation to TSH level in group A after 6 months of metformin treatment, 1.99 $\pm 1.42 \mathrm{mU} / 1, \mathrm{p}<0.05$. There were no significant differences of basal TSH, FT3 and FT4 levels in groups A and B compared to group $\mathrm{C}$ with metformin therapy longer than five years, with an insignificantly lower TSH and FT4 values in group C.

\section{Discussion}

Metformin is now considered first-line drug in the treatment of type 2 DM. The mechanisms of its action are different, but mainly refer to improve insulin sensitivity. Some authors presented data on the possible effect of metformin on TSH level and consequently on thyroid function. Taking into account the significant association between diabetes and hypothyroidism, in our study we aimed to determine the potential effects, and therefore the clinical implications of metformin in patients with and without thyroid function disorder. The data on this issue are limited and not consistent (9).

The results of our research show that six months of metformin therapy resulted in statistically significant reduction in TSH level only in the group of patients with pre-existing hypothyroidism (group B), and that this reduction was greater than in group A. In group A the application of metformin leads to an insignificant reduction of TSH level, except in TPOab positive subjects, in which a statistically significant reduction in TSH level emerged after six-month administration of metformin. The results imply that metformin has TSH lowering effect, but only in patients with preexisting thyroid dysfunction, which may include the existence of a chronic autoimmune thyroiditis (TPOab positivity).

Cappelli et al in their large retrospective study reported that metformin has a TSH lowering effect in patients with hypothyroidism and euthyroid persons with high-normal TSH, which is consistent with our results (7). Results of our study showed no significant difference in reducing TSH levels in euthyroid diabetic patients depending on its basal values, but with a certain difference. In fact, in the group A there is greater reduction of TSH levels in subgroup with higher TSH (2-4.6 mU/1), while in group B significantly lower levels of TSH have been reached regardless of the basal TSH levels. Cappelli and colleagues do not show significant effects of metformin in euthyroid persons with type $2 \mathrm{DM}$, and at the same time conclude that metformin has a neutral effect on 
TSH in euthyroid patients (10). As opposed to our results, these authors do not emphasize the connection with positive TPOab or existing autoimmune thyroiditis, but primarily highlight the importance of high-normal TSH ( $>2.5 \mathrm{ml} / \mathrm{l})(7)$. Rajput et al in patients with subclinical hypothyroidism, but with not existing diabetes, have shown that metformin reduces TSH levels only in TPOab positive person (11). Similar results are presented by Diezz JJ, where in type $2 \mathrm{DM}$ patients and normal thyroid function there is no link between the TSH level and treatment with metformin (12). Fournier et al, also showed the effect of metformin on TSH only in a group of patients with treated hypothyroidism, while there is no effect on TSH levels in euthyroid persons (13). Group C results analysis show that long term use of metformin, over five years, does not lead to significant reduction of TSH levels in euthyroid DM type 2 patients in comparison to the six-month therapy (group A), although obtained TSH value is slightly lower in group C.

Fournier et al point out that in fact TSH lowering effect of metformin is highest in the first 90 to 180 days of therapy (13). Cappelli et al also showed more significant decrease in TSH level in euthyroid persons after twelve months of metformin therapy (10). According to duration of metformin therapy, most of the data complied that there is no significant decrease of TSH levels in long term usage of metformin and that his TSH lowering effect is not tipe-dependent, both in euthyroid and hypothyroid DM type 2 patients $(14,15)$. Various hypotheses have been proposed to explain the mechanisms by which metformin exerts its TSH lowering effect, but the exact mechanism remains unclear. Metformin may change the affinity and number of thyroid hormone receptors (16). One involves the action of metformin on 5-AMP-activated protein kinase (AMPK) (10). In the liver, metformin activates AMPK and suppresses hepatic gluconeogenesis, bur has inhibitory effect on hypothalamic AMPK activity, which may counteract T3 effects at hypothalamic level (17). The potential interaction of metformin and levothyroxine in digestive tract seems unlikely, because TSH lowering effect was observed in patients who were not treated with levothyroxine (18). We could assume that considerable number of our patients with high normal TSH might in fact have a sublicinical hypothyreodism.

\section{Conclusion}

The results of our study show that metformin has TSH lowering effect in patients with type $2 \mathrm{DM}$ and hypothyreoidsm, but also in euthyroid TPOab positive, levothyroxine naive patients. Basal TSH did not play an essential role to the degree of reduction. Also, we have shown that the TSH lowering effect of metformin is not dependent on long term metformin therapy.

\section{References}

1. Wu P. Thyroid disorders and diabetes. It is common for person to be affected by both thyroid disease and diabetes. Diabetes self-menagement 2007; 24 (80-82): 85-87.
2. Feely J, Isles TE. Screening for thyroid disfunction in diabetics. BMJ 1979; 1: 1678.

3. Goldman -Levine. Pharmacotherapy 2011; 31 (Suppl 12): 44-53.

4. Abdulrahman RM, Boon MR, Sips HC, Guigas B, Rensen PC, Smit JW, Hovens GC. Impact of metforminand compound C on NIS expression nad iodine uptake in vitro and in vivo:a role for CRE in AMPK modulation of thyroid function. Thyroid 2014; 24 (1): 78-87.

5. Vigerski RA, Filmore-Nassar A, Glass AR. Thyrotropin supresion by metformin. J Clin Endocrinol Metab 2006; 91 (1): 225-227.

6. Isidro ML, Penin MA, Nemina R, Cordido F. Metformin reduces thyrotropin levels in obese, diabetic women with primary hypothyreoidism on thyroxine replecement therapy. Endocrine 2007; 32 (1): 79-82.

7. Cappelli C, Rotondi M, Pirola I, Agosti B, Formenti A, Zarra E, Valentini U, Leporati P, Chiovato L, Castelano M. Thyreotropin levels in diabetic patients on metformin treatment. Eur J Endocrinol 2012; 167 (2): 261-265.

8. Rezzonico J, Rezzonico M, Pusiol E, Pitoia F, Niepornniszcze H. Metformin treatment for small benign thyroid nodules in patients with insulin resistance. Metab Syndr Relat Disord 2011; 9 (1): 6975.

9. Shailendra D, Mrinal D, Subbaratnam Y, Prasuna G. Effect of merformin on thyroid stimulating hormone in euthyroid type 2 diabetes mellitus patients. J Evid Based Med Healthcare 2015; 19 (11): 2837-2842.

10. Cappelli C, Rotondi M, Pirola I, Agosti B, Gandossi E, Valentini U, De Martino E, Cimino A, Ghiovato L, Agabiti-Rosei E, Castellano M. TSH-lowering effect of metformin in Type 2 diabetic patients. Diabet Care 2009; 32: 1589-1590.

11. Rajput R, Saini M, Rajput M, Shankar V. Effects of metformin on thyroid function in patients of subclinical hypothyreoidism. J Endocrinol Metab 2013; 3 (4-5): 105-110.

12. Diez JJ, Iglesias P. Relationship between serum thyrotropin concentration and metformin therapy in euthyroid patients with type 2 diabetes. Clin Endocrinol (Oxf) 2013; 78 (4): 505-511.

13. Fournier JP. Yin H. Hoi Yun Yu O. Azoulay L. Metformin and low levels of thyroid-stimulating hormone in patients with type 2 diabetes mellitus. CMAJ 2014; 186 (15): 1138-1145.

14. Rotondi M, Cappeli C,Magri F et al. Thyroidal effect of metformin treatment in patient with polycystic ovary syndrome. Clin Endocrinol (Oxf) 2011; 75 (3): 378-381.

15. Morteza Taghavi S, Rokni H, Fatemi S. Metformin decreasesthyrotrpin in overweight womenwith polycystic ovarian sundrome and hypothyroidism. Diab Vasc Dis Res 2011; 8 (1): 47-48.

16. Krysiak R, Okopien B. Thyrotropi-lowering effect of metformin in patient with resistance to thyroid hormone. Clin Endocrinol (Oxf) 2011; 75 (3): 404-406.

17. Bogachus LD, Turcote LP. Genetic downregulation of AMPK-alpha isoforms uncovers the mechanism by wich metformin decreases FA uptake and oxidation in sceletal muscle cells. Am J Physiol Cell Physiol 2010; 299 (6): 1549-1561.

18. Khan NF, Harrison SL, Rose PW. Validity of diagnostic coding within the General Practice Research Database:a systematic review. Br J Gen Pract 2010; 60 (572): 128-136. 